\title{
SOCIAL IMPACTS OF IPM-FFS ON URBAN AND PERI-URBAN VEGETABLE PRODUCERS IN COTONOU, BENIN
}

Lund T*1,2, Nyborg $I^{2}$, Rahman $\mathrm{MH}^{3}$ and MG Sæthre ${ }^{1}$

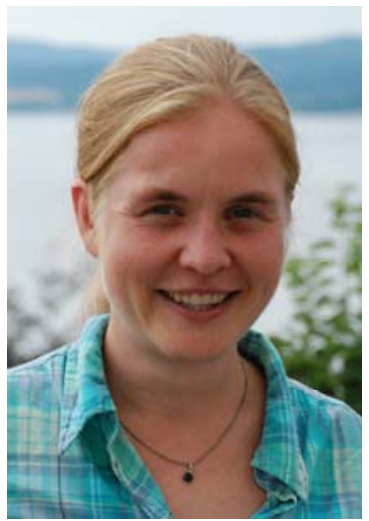

Trine Lund

*Corresponding author email: trilund@gmail.com

${ }^{1}$ Norwegian Institute for Agricultural and Environmental Research, Fr. A. Dahlsvei 20, 1432 Ås, Norway

${ }^{2}$ Department of International Environment and Development Studies, Norgaric, Norwegian University of Life Sciences, P.O. Box 5003, 1432 Ås, Norway

${ }^{3}$ Department of Chemistry, Biotechnology and Food Science, Norwegian University of Life Sciences, P.O. Box 5003, 1432 Ås, Norway. 


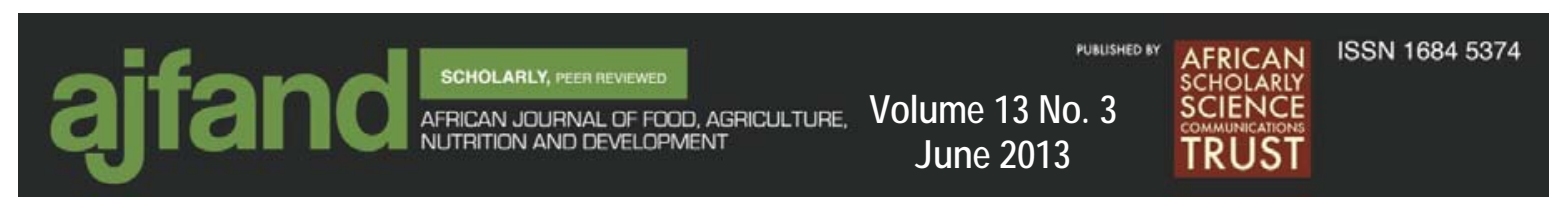

\section{ABSTRACT}

Shifting from scientist-led top-down approaches in agricultural development to participatory approaches putting farmers and their knowledge in the center requires scientists and farmers to play new roles, changing social relationships between them, and among farmers themselves. Using mainly qualitative data and analysis, this paper reports social impacts (social relations, social empowerment and sharing of IPM information, and sustainability and institutionalization of IPM) for vegetable producers in an integrated pest management (IPM) project using farmer field schools (FFS) in Cotonou. Forty-three vegetable producers were chosen for semi-structured interviews. The project led to social empowerment of the vegetable producers and initiated a process of creation and sharing of IPM knowledge and building of social relations within and between the vegetable gardens. The participants realized they were sources of information for each other, and IPM knowledge was shared without the benefit or restriction of social networks. However, this study revealed several factors hindering the development of improved social relations among the vegetable producers and between these and the scientists and steering committee members, which in turn may result in lack of continuation and institutionalization of IPM activities. To overcome these obstacles, this research suggests that similar IPM-FFS projects encourage (1) a transparent selection process, (2) improvement of the Trainer of Trainers' facilitation skills for better quality FFSs and improved sharing of complex information like agro-ecosystem analysis and beneficial insects, (3) building trust and confidence between the participants and scientists, (4) giving the ToT participants, community organizers and farmer organizations ownership of the project by giving them responsibility for creating post project plans to spread and institutionalize IPM of IPM-FFS activities and (5) facilitating the participants during and after the project in improving social relations and accountability. The results also draw lessons on how scientists and vegetable producers have or should have changed their roles to sustain and institutionalize IPM, such as the scientists and project leaders need to focus even more on their interactions with vegetable producers, enhancing their role as facilitators in initiating equitable processes of sustaining and institutionalizing IPM in the vegetable gardens.

Key words: IPM-FFS, Empowerment, Relations, Information sharing 


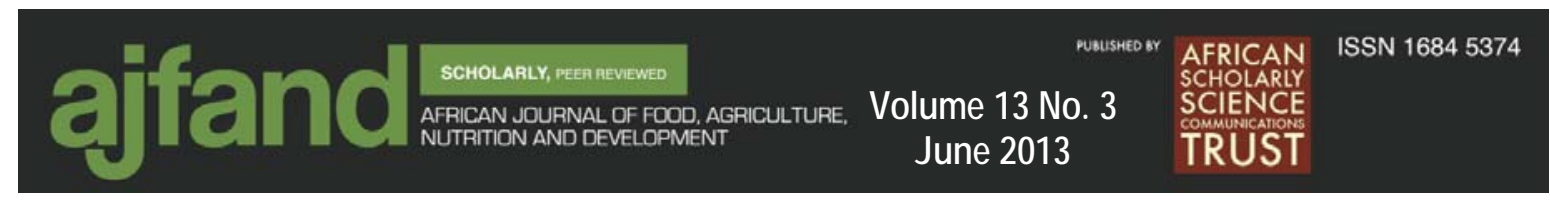

\section{INTRODUCTION}

More than half of the human population live in urban areas [1] and poverty and malnutrition have increased along with urban growth [2]. Urban and peri-urban (UPU) vegetable production may reduce these negative prospects by making productive use of under-utilized resources (like vacant land, treated wastewater, recycled waste and unemployed labour) [3] to improve nutrition, food security and livelihoods (jobs and income) [2]. Despite the fact that a large proportion of the population is involved in UPU agriculture, attention to this sector has been absent from most national, regional and international agricultural research organizations and networks in Africa with a few notable exceptions [4]. Up to two-thirds of UPU households in developing countries are involved in agriculture, thus a "safe" development of the sector, avoiding environmental and health problems caused by excessive and misuse of agro-chemicals, is needed. One relevant approach is integrated pest management (IPM), which aims to maintain the balance of the ecosystem and reduce the use of synthetic pesticides by integrating plant health and a variety of pest management methods [5]. While traditional 'transfer of information' approaches only work with simple technologies in simple systems, complex technologies, like IPM, introduced into complex systems, require an adaptation phase where first adopters and researchers go through experiential learning cycles to improve the adaptability of the technology [6]. In IPM, biology and ecology of pests and natural enemies along with various pest control technologies need to be understood by the farmers to become an integrated part of good agricultural practices. Thus the educational method of farmer field school (FFS), focusing on farmers as active agents of change, is often used to implement IPM [7].

The FFS philosophy is based on production of a healthy crop, conservation of natural enemies, performance of regular field observations and belief of the expertise of farmers on their own fields. Thus FFS seeks to enhance the participants' understanding and adaptation of knowledge into their own lifeworlds through experiential learning. By learning about the interactions of the agro-ecosystem and developing their analytical skills, the farmers should be empowered to realize which factors are within their control and also to "drive the demand for scientific information" [8]. For this to happen, the leaders of the FFS sessions should not act as experts delivering advice, but rather as facilitators who create a process of information exchange emphasizing the journey rather than the destination [9]. Empowerment, which is a "multi-dimensional social process that helps people gain control over their own lives" [10], occurs in various dimensions (like sociological, psychological and economic), and on different levels (like individual, group, and community), and is a key concept in trying to understand FFS dynamics.

In Asia, where the IPM-FFS approach was initiated in rice growing areas decades ago, positive social changes [7] and beneficial human and environmental health effects have been reported [for example, 11, 12-14]. As a result of these positive changes, the IPM-FFS approach has been adapted to cover other crops and topics and FFSs are running in at least 87 countries throughout Asia, sub-Saharan Africa, Latin

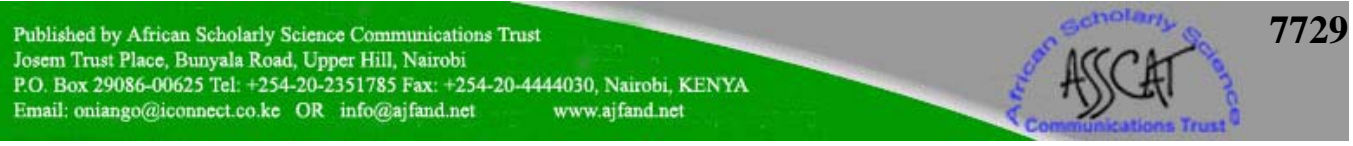




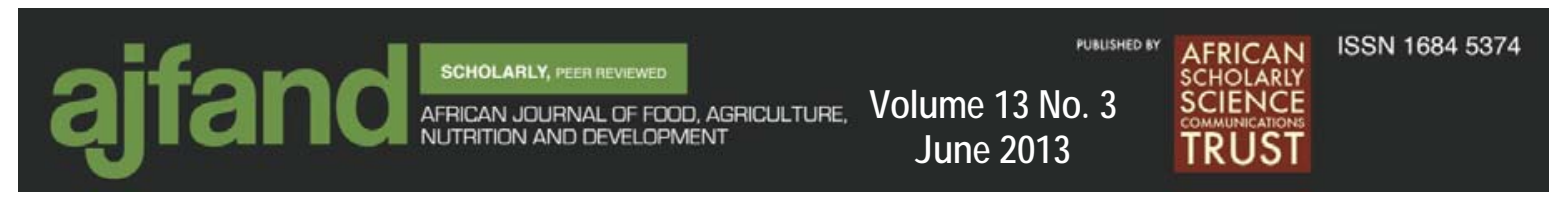

America and the Caribbean, Near East and North Africa, Central and Eastern Europe, and it has recently been started in the United States and Western Europe [15]. Integrated pest management is promoted by the Food and Agriculture Organization of the United Nations (FAO) as the main approach to plant protection and FAO has regional programs in the Near East, Asia and West Africa [16]. Since FFS was first introduced in Africa (Ghana 1995 and Mali 1997), it has spread to many countries in the region and development projects, researchers and farmers are experimenting how to adapt FFS to African cultures and production systems [17]. IPM-FFS programs in East Africa have already started to reveal positive effects regarding knowledge, production, pesticide use, income and poverty [18].

In Cotonou, Benin, important challenges among vegetable producers include excessive and faulty use of synthetic pesticides and low knowledge about pests of vegetables [19]. In 2003, the International Institute of Tropical Agriculture's (IITA) station in Benin, therefore, initiated the project "Healthy Vegetables through Participatory Integrated Pest Management (IPM) in Urban and Peri-Urban Gardens of Benin” (hereafter referred to as the Project). As one of the first vegetable IPM-FFS carried out in West Africa, the Project aim was to improve local farmers' food security through IPM information, awareness and capacity building [19]. There is no agreement on what and how to measure impacts of FFS [20] as FFS approaches always must be adjusted to the local conditions [7]. Since FFSs are tailored to effectively disseminate information and technology to certain regions and farmer groups and often focus on specific crops, the impacts must be analyzed case-by-case [21]. Considering the expanding UPU vegetable cultivation there is a need to learn how to better introduce and adapt IPM-FFS in these environments. The FFS approach has resulted in increased self-confidence and social changes and the reflective critical thinking and collective action developed through the FFS approach have often resulted in farmers challenging authorities and information providers [15]. However, as there may be many factors that spur or hinder collective social action and continuation of such initiatives, this paper will address these issues by assessing social impacts of the IPM-FFS Project in UPU areas of Cotonou, Benin, by focusing on; (1) social relations, (2) social empowerment and sharing of IPM information (3) and sustainability and institutionalization of the IPM-FFS. A better understanding of the social effects of an IPM-FFS program in its starting phase will contribute to the development of UPU vegetable IPM-FFS in West-Africa and elsewhere.

\section{MATERIALS AND METHODS}

\section{Introduction to the UPU area and the IPM-FFS Project}

At the time of this survey there were 15 major vegetable gardens in Cotonou, any of which may be closed at any time as the vegetable producers do not own the land or have formal contracts with the landowner. Each garden has several cooperatives. The producers, who have a defined cropping area of several beds $(6 \times 1.2 \mathrm{~m})$ each, mainly produce for the local market. Many of them also have additional work outside the gardens. The farmer organization (Union communale des producteurs, UCP), created

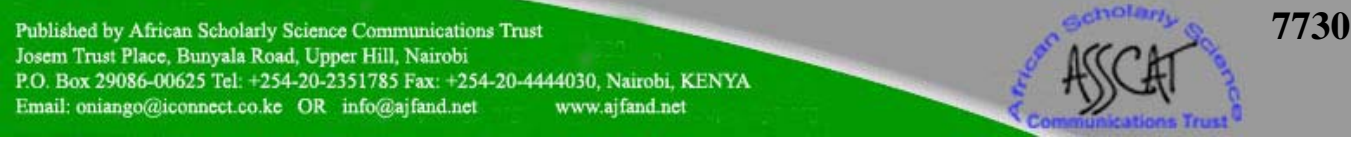




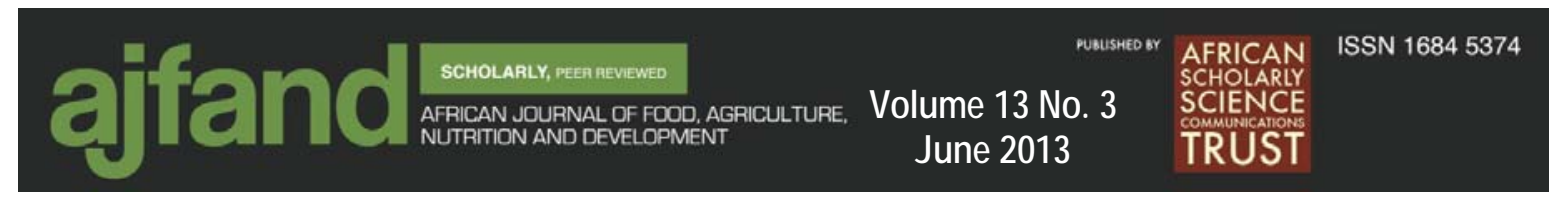

by the government of Benin on request from European NGOs, includes all farmers in Cotonou (about 700), but it is a weak organization. The UCP Cotonou consists of a president, treasurer, secretary, eight farmer trainers and a communication officer, all volunteering. In southern Benin, biological risks (pests) are ranked as one of the three main constraints to vegetable production [19]. Based on the vegetables facing highest economic damage by pests and receiving the largest quantity of pesticides, the Project focused on cabbage (Brassica oleracea L. capitata L.) and lettuce (Lactuca sativa L.) in the first Training of Trainers (ToT) cycle (March to May 2003), and gboma (a variety of the African eggplant, Solanum macrocarpon L.) and carrot (Daucus carota L. sativus Hayek) in the second (January to March 2004) [19]. Twelve vegetable gardens participated in the first and 14 in the second Project cycle, respectively.

The Project was designed for participatory research/learning (Figure 1), focusing on "technical, social and financial empowerment of local producer groups, women and unemployed youth" [19]. In the participatory research phase, a list of the most important pests, cropping and pest management practices was made. In the participatory learning phase, 37 (6 female/31 male) vegetable producers participated in the ToT where they experimented to find the best cropping and pest management practices. The ToT participants were then supposed to arrange FFS with minimum four vegetable producers each to share this knowledge, thus at least 65 vegetable producers were to participate in the FFSs. However, due to recruitment problems, the actual number of FFS participants was much lower and the female/male ratio not known. The Project was designed to include illiterate persons as ToT participants, and to have the FFS and ToT sessions the same week to reduce the time between learning and teaching. However, the actual selection criteria for ToT participation were (1) belonging to a UCP cooperative, (2) being literate, (3) being available to participate in trainings and (4) being willing to share knowledge. As more female (57\%) than male (6\%) respondents were illiterate, the 'literacy' criterion excluded more women than men. The ToT participants, who were of the more affluent vegetable producers (older, more years of education and experience in vegetable cultivation, and having more beds than average), were selected by the cooperative leaders in a meeting at Houeyiho (the largest production site/garden in Cotonou), followed by a workshop regarding the curriculum and program organization. 

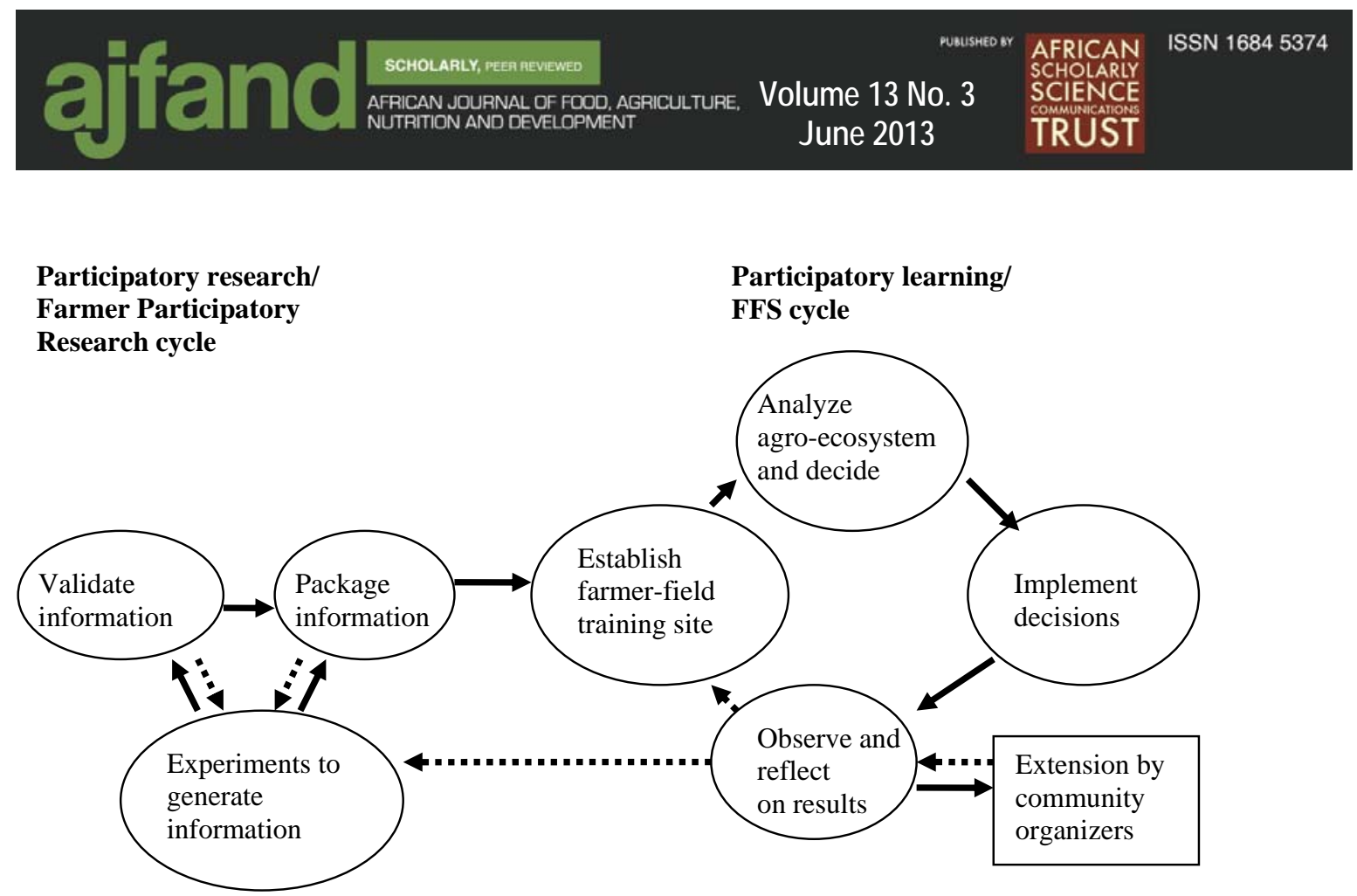

Figure 1: Participatory research and learning cycle in the Project [19].

The Project's steering committee was comprised of representatives from the National Institute of Agricultural Research in Benin (INRAB), the Plant Protection Service (SPV), the University of Abomey-Calavi (UAC, Cotonou), OBEPAB (NGO specialized in organic agriculture), the UCP and the Beninese Chamber of Trade and Industry. This committee was responsible for the topics covered in the ToT sessions; pest knowledge and management methods (especially biological alternatives to synthetic pesticides), plant health, sanitation, safe use of pesticides and economics of plant protection and production. In the ToT sessions, the participants performed weekly agro-ecosystem analysis (following the crops' life cycles) and made management decisions which were discussed in plenum. To spread the IPM knowledge and institutionalize IPM activities, five ToT participants (1 female) were trained as community organizers whose tasks were to quality control the FFSs and develop action plans (with the steering committee) for the continuation of these activities. The UCP representatives in the steering committee were to keep the community organizers informed about the Project [19].

\section{Sampling}

The research was conducted in UPU areas of Cotonou between October 2006 and January 2007. Three vegetable gardens where ToT/FFS cycles had been held (Houeyiho, ONEPI, Gbegamey) were selected according to the following criteria; accessibility (short travel distance within Cotonou) and at least some of the crops in the Project were cultivated there (carrot, lettuce, cabbage and gboma). At Houyieho, 334 vegetable producers (54 female) were cropping on 15ha, at ONEPI 42 producers (1 female) on 2,5ha, and at Gbegamey 30 producers (1 female) on 2ha. A transect walk [22] was done in all three gardens to get preliminary information about the area. Convenience sampling of the snowball type [23] was used to identify potential 


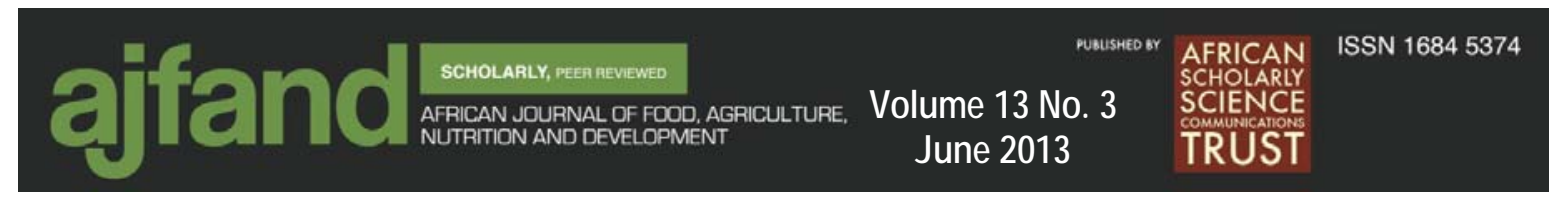

respondents among the vegetable producers, and from these, respondents were selected based on gender, age, education, economic and social status so all socioeconomic categories were represented. Fifteen ToT ( 1 female/14 male) (the total equals $41 \%$ of the total ToT in the Project), nine FFS (1/8) and 19 non-participants (3/16) were selected to compare the Project's impact on participants (ToT and FFS) and non-participants. The percentage of sampled FFS and non-participants based on the number in the Project could not be calculated as the latter number was not available. In total, 43 vegetable producers were selected for semi-structured interviews with open ended questions [22]. Female and male respondents were interviewed separately for open discussions.

Group discussions were held on the following topics: sharing of IPM information, the training's impact on the farmers' ability to discuss, work in groups or reach consensus, participation/non-participation, post-IPM activities, selection procedure and responsibilities for ToT and community organizers and their relationship with the steering committee and IITA. Male group discussions were conducted at Houyieho, with ToT (4) and non-participants (2), at ONEPI with ToT (2), FFS (2) nonparticipants (2) and with the community organizers (2). It was difficult, however, to get in contact with and arrange the same level of group discussions with women. Since women were very busy and also worked outside the gardens, few were encountered when walking through the gardens. Also, not all women encountered were willing to participate, and those who were willing were interviewed individually as key informants. Individual interviews on the same topics discussed with the male focus groups were held with one ToT (female), two FFS (one female and one male) and one non-participant (female) at Houyieho, and with one ToT (male), one FFS (female) and one FFS (male) at Gbegamey.

Cross checking was applied to get perceptions of the Project and the vegetable gardens from different angles and to capture as accurate a picture as possible. Thus 13 key informant interviews were held with people directly involved in the Project (members of the steering committee from OBEPAB, SPV, INRAB, IITA-Benin and UCP) or having knowledge about pesticides (quality control, users and the market), cropping techniques and social issues in the gardens (an ambulant salesman of agrochemicals; two elderly, experienced vegetable producers; a public establishment to promote quality in production and services (CEBENOR); the public extension service (CeRPA) and the local NGO Eco-santé).

An interpreter was used for all the interviews with the vegetable producers so these were held in the language preferred by the respondents: Fon or French. All the semi structured interviews were conducted by the same interviewer reducing the error margin [23].

\section{Analysis}

The analysis is mainly qualitative [23], with data from individuals and focus groups being coded, categorized and structured within three main areas: (1) social relations; (2) social empowerment and sharing of IPM information; and (3) sustainability and

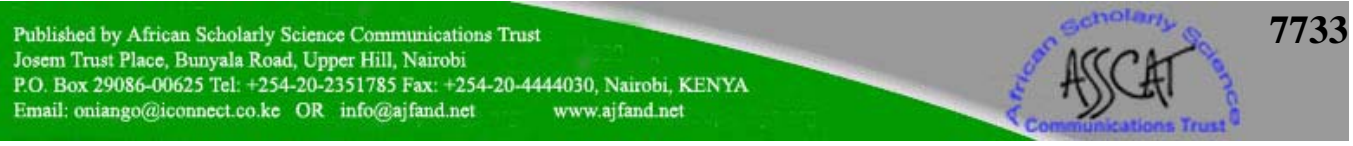




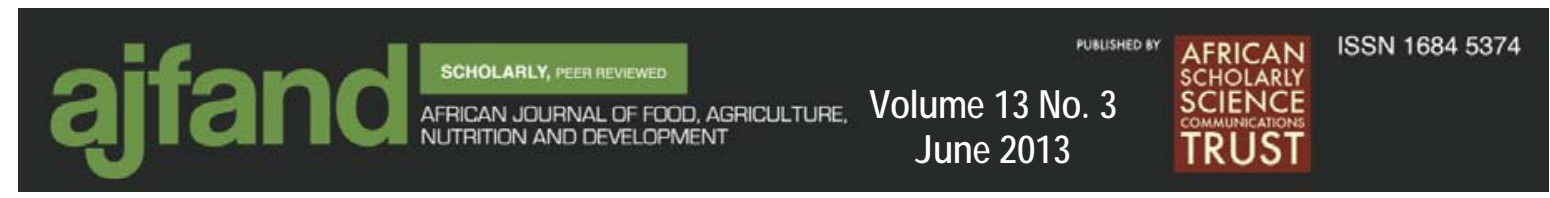

institutionalization of the IPM-FFS. "Social relations" refer to how the vegetable producers and the Project steering committee relate to each other and to whom they relate. "Sharing of IPM information" investigates which, how and with whom information from the Project was shared. These categories look at whether the whole community of vegetable producers were included or excluded in the process of generating and spreading IPM information, and may also explain to what extent IPMFFS was institutionalized in the gardens. To evaluate the Project's impact on social empowerment, which "promotes independence and self-determination, and facilitates people's participation in their communities" [24], this study focuses on whether the participants became more confident talking in public; were better in communicating, negotiating and arguing; discussed IPM with new people after the training and better reached consensus and cooperated in groups. Finally, "sustainability and institutionalization" looks at whether the IPM activities were sustained and institutionalized explained by roles played by the various groups in the Project (Project leaders from IITA, Project steering committee, community organizers, ToT). The numerical data was analysed using Excel.

\section{RESULTS}

Social relations among the vegetable producers and between them and IITA staff According to the respondents, the Project had no impact on the power relations in the gardens, or on the Project participants' ability to reach consensus and cooperate in groups. In the surveyed gardens individualistic thinking and mistrust between the vegetable producers and the leadership of the gardens existed as expressed by a producer at Houeyiho (28.12.2006): "The production groups in Houeyiho are run more like a company than a cooperative, because the leaders decide without consulting the producers. In a cooperative everybody should decide and the leaders should work in the interest of all producers".

Staff from IITA was seen more frequently in the gardens after the Project, but mostly visited the same ToT participants each time, which created jealousy from the other producers as explained by a non-participant (Houyieho, 29.12.2006): "Only some producers get to contribute with their land to experiments and get paid, but everybody should get this opportunity. If more producers got this opportunity, they would participate in the FFSs. The IITA staff only visit their experimental plots and don't inform the other producers about their research." The non-participants' anger and feeling of exclusion increased by the fact that many of them had not been informed about the ToT selection meeting, and this reduced their willingness to participate in the ToT run FFS sessions. Although 15 of 19 non-participant respondents wanted to participate in the Project, a ToT participant (Houyieho, 17.12.2006) experienced that, "It was difficult to get FFS participants because the producers didn't understand what the Project was about and didn't see the benefits of participating." The nonparticipants found it more desirable to participate in the ToT than the FFS, due to financial reasons (they considered the money the ToT participants received for transport to meetings and materials for their FFS sessions as "payment”) and quality reasons (higher number of beds, more crop varieties used for experimentation, as well

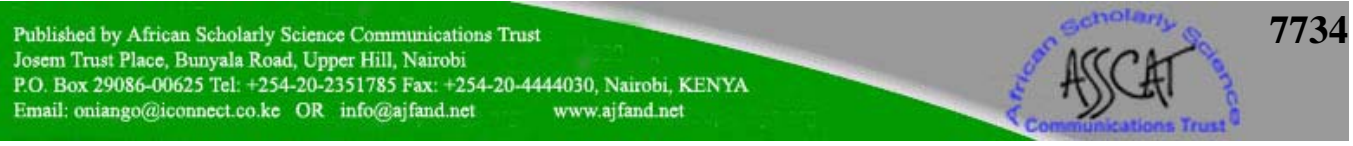




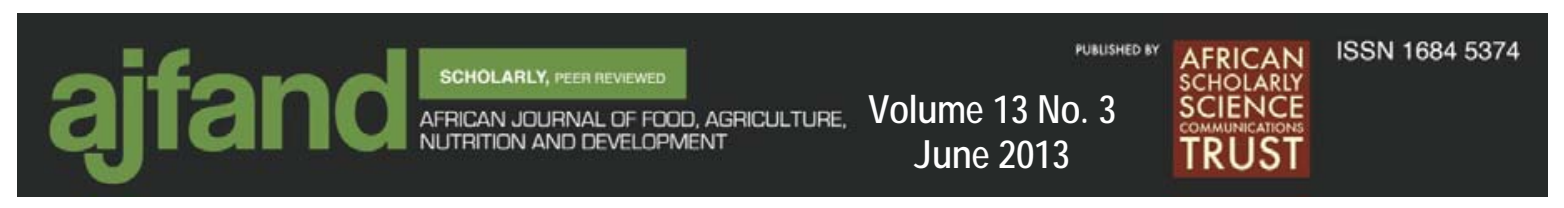

as three ToT did not conduct any FFS), so when they were not selected for ToT they refused to attend the FFSs.

Due to lack of assistance from extension service and research institutions, the respondents were used to relying on themselves, thus they did not think they could ask institutions for advice or that IITA would consider their problems. The ToT participants did not see IITA staff as equals, and lack of reliability and trust from both sides existed. However, the ToT participants appreciated the social relations arising between the vegetable producers of different gardens during the Project as expressed by a ToT participant (Houyieho, 15.12.2006): "Earlier, if we went to other vegetable gardens the vegetable producers may think we wanted to buy vegetables, they didn't even know we were vegetable producers, but now we share information”.

\section{Social empowerment and sharing of IPM information}

The Project empowered the participants regarding confidence in public speaking; ability to communicate, negotiate and argue and to discuss IPM with new people they did not know prior to the training (Figure 2). While eight of 15 ToT respondents felt that participating in the ToT/FFS training had enhanced their confidence in public speaking, only two of nine FFS respondents felt likewise. Increased knowledge was the main reason for improved confidence, and resulted in participants taking the floor more often in meetings and one ToT becoming secretary in her cooperative. Nine of 15 ToT, but only three of nine FFS respondents felt improved ability to communicate, negotiate and argue due to the training. Both ToT and FFS participants found it easier to explain how and why to do certain management practices after the training, due to improved ability to reflect upon own activities. Nine of 15 ToT, but only two of nine FFS respondents discussed IPM with new people after the training. Many respondents felt free to ask one particular ToT participant, who was easily approachable and advised persons within and outside his garden. Some respondents, who were not used to discussing with other producers, started giving advice when passing by plots and observing management problems. Many participants felt empowered to take on new roles, but the impact was lower for the FFS than the ToT participants. 

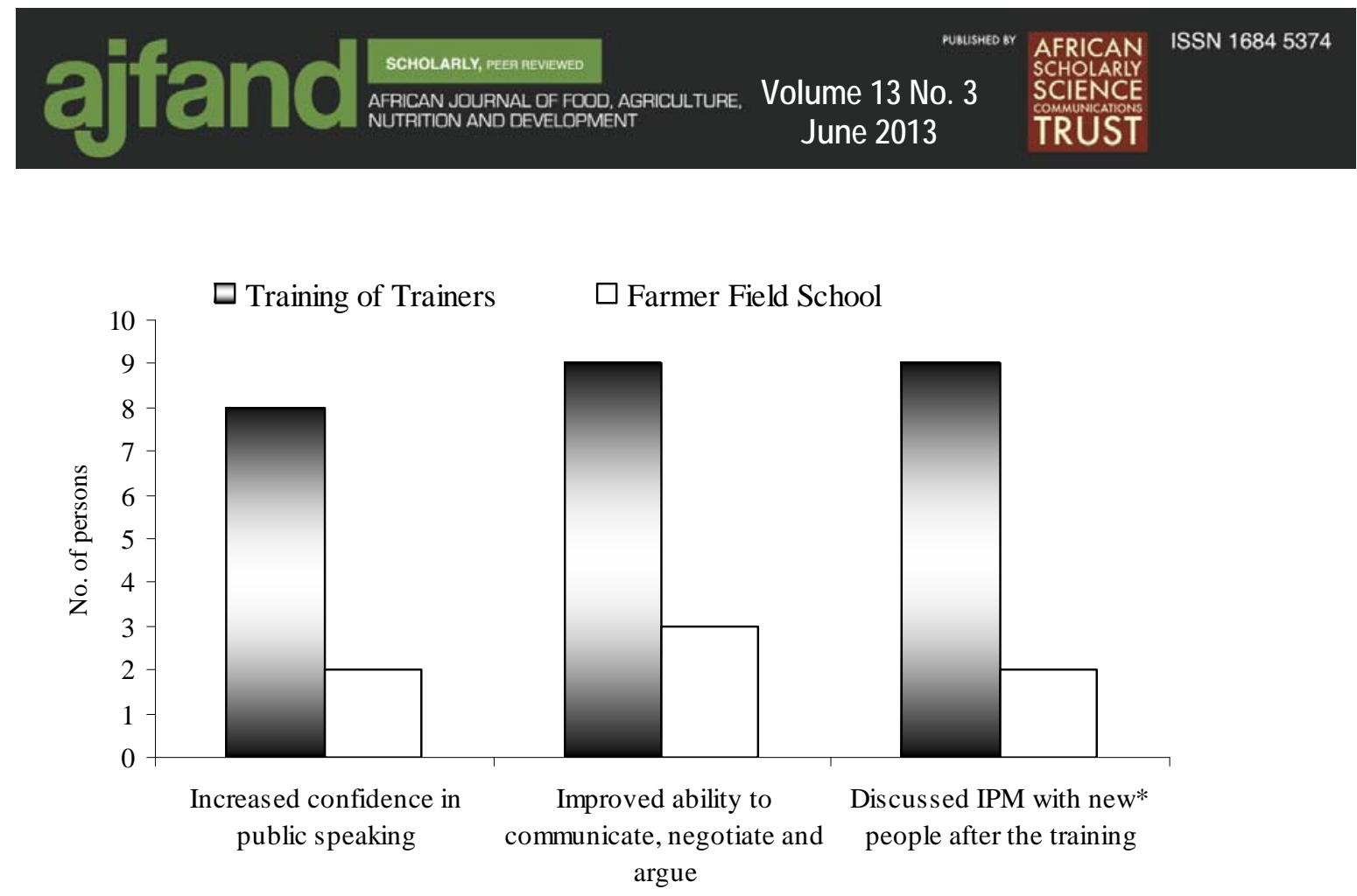

*people they did not discuss with prior to the training

Figure 2: ToT and FFS participants' perceived social empowerment according to selected criteria. Total number of ToTs and FFSs interviewed were 15 and nine, respectively

The discussion of problems and solutions in the gardens increased due to the Project. A fairly high number, 11 of the 15 ToT, and six of nine FFS respondents had shared IPM information (including with people they knew prior to the training), and realized that they were sources of information for each other. The information was mostly shared with neighbours and friends, and sometimes spread to other gardens even outside Cotonou. Quite many ToT and FFS respondents also shared information with random people when passing by plots or asked for advice, thus much information was shared without the benefit or restriction of social networks. The ToT participants were more accessible to the other vegetable producers than the researchers and represented key resources in spreading information and creating knowledge.

The Project participants mostly taught specific techniques rather than agro-ecosystem interactions. The ToT respondents taught how to observe vegetables and pests, but the majority emphasized counting of pests and only one taught about agro-ecosystem analysis. The FFS respondents mostly taught to use organic fertilizer and manure, and to reduce, improve or stop the use of synthetic pesticides. While the ToT/FFS participants shared their IPM information by demonstrating knowledge/techniques in praxis and/or explaining it theoretically, a larger proportion of the ToT than the FFS respondents used demonstrations (Figure 3). 

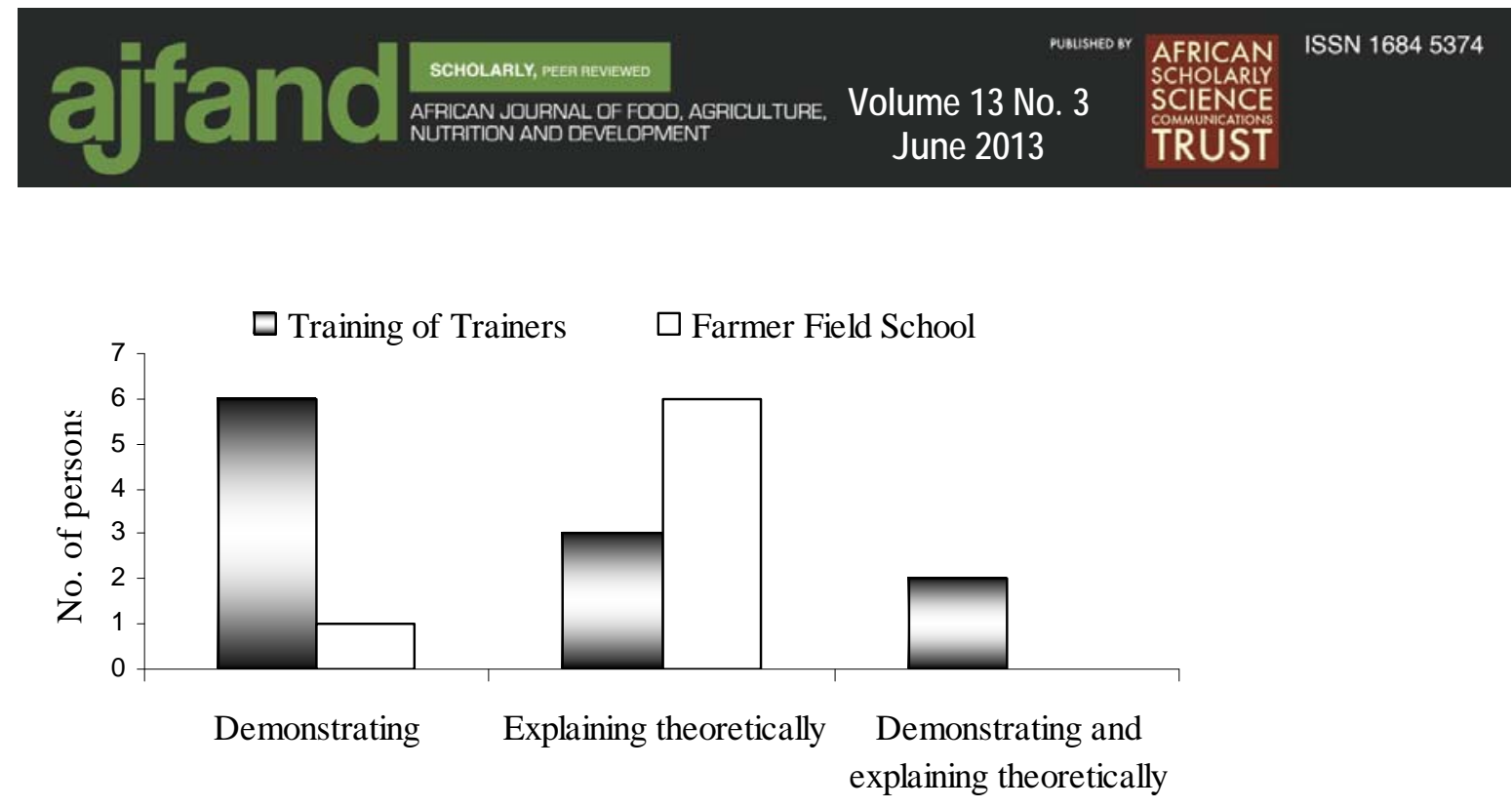

Figure 3: Way of sharing information*

*based on the 10 ToT and six FFS participants who shared IPM information

\section{Sustainability and institutionalizing of the IPM-FFS}

As the ToT participants and community organizers were not involved in any endevaluation or in forming action plans for post-IPM activities, they felt they had no role to play when the Project ended. The UCP representatives in the Project steering committee, the ToT participants and the community organizers lost their motivation and commitment to the Project as they were not given responsibility and information, as expressed by the UCP leadership (Houyieho, 06.01.2007): "The monitoring committee met once a month, but after some time the meetings stopped. The community organizers got information from the UCP representatives, so when there were no meetings they got no information. Finally, IITA took over the responsibilities from the UCP representatives, and managed the Project alone". Also the NGOs in the Project steering committee were not given responsibility to plan post-IPM activities, as noted by a committee member: "In the ToT/FFS IITA had the leading role, but after the Project all stakeholders retired” (Gbégamey, 10.01.2007).

\section{DISCUSSION}

\section{Social empowerment and sharing of IPM information}

The Project participants realized the value of discussing IPM with other vegetable producers and could better explain how and why they chose certain management practices. However, although the ToT and FFS participants felt increased confidence in talking in public, little IPM knowledge was passed on in the gardens' formal forums. While results from Ghana and Mali also show that already existing local structures were not used to disseminate IPM messages [17], the FFS participants in Gerung in Indonesia shared IPM information in social farm gatherings [7]. In FFS, a challenge is to enhance the diffusion effect from trained to non-trained farmers [25], and social capital, which can be generated by social interactions, may enhance the sharing of agricultural information as it (1) reduces the cost of acquiring information, (2) increases the reliability of the information and (3) facilitates cooperation and

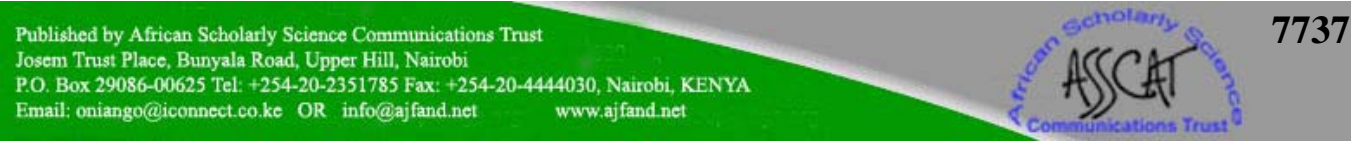




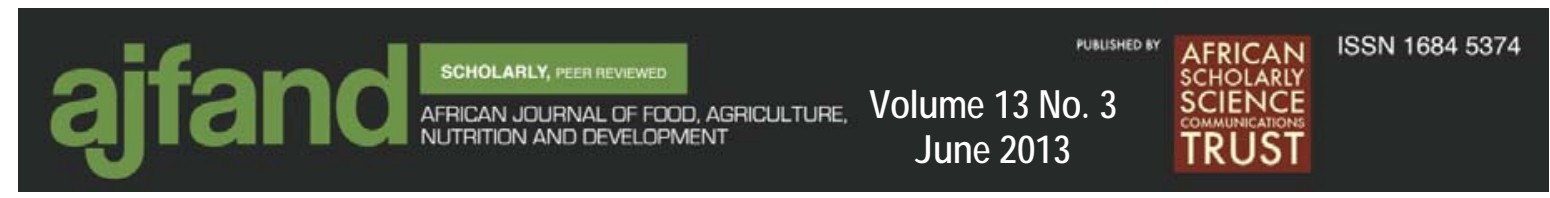

willingness to share information [26]. In Cotonou, many ToT participants shared IPM information without restriction or benefit of social relations, and as they were more accessible than the researchers they represented key resources in spreading information and creating knowledge. This finding is contrary to other research suggesting that agricultural information mainly diffuses through social networks and may not be available to all in the community, like in the cowpea FFS in Benin, where IPM information was shared within the participants' social networks [27, 28, 29]. Almost none of the Project participants shared information about the agro-ecosystem, which equals other studies finding that this complex information is the most difficult aspects of IPM to disseminate [13]. Also Ghanaian FFS graduates (cocoa farmers) were more likely to inform other farmers about how to implement management practices, but rarely mentioned agro-ecological principles [30]. The ToT respondents in Cotonou did share information on how to observe vegetables and pests, the first step of agro-ecosystem analysis, and more ToT than FFS participants shared information by demonstrations, indicating less training in practical teaching for the latter group.

That more ToT than FFS participants reported increased confidence in public speaking and increased ability to communicate, negotiate and argue is likely to be due to more intensive ToT than FFS sessions. In the ToT sessions the participants had to explain and defend their decisions to people they did not know (from various gardens) and to a larger audience than the FFS participants. While the ToT session leaders were scientists and/or leaders of NGOs trained to be facilitators, the ToT participants leading the FFS sessions had less training. As the ToT and FFS sessions were held during the same week, the ToT participants did not have enough time to reflect upon their own learning processes or develop their facilitation skills before training others. In addition, many FFSs did not produce all the Project vegetables (cabbage and lettuce, gboma and carrot) in both Project cycles, clearly reducing their intensiveness. Also FFS graduates in Ghana reported improved skills in public speaking, reaching consensus as a group and effective group work as a result of the training in addition to increased respect and accept for others' views and some participants acquired new social positions due to these gained skills [30].

While money also influenced the willingness to participate in the UPU vegetable Project, the FFS participants in the cowpea IPM-FFS in rural Benin did not ask for money, but rather contributed labour [31]. This motivational difference may be due to different lifestyles, goals and livelihood situations. The fact that the UPU vegetable producers did not own the land and had additional income generating activities may have induced a short-term thinking of exploiting the land, making time investment in IPM activities less interesting. As rural farmers often own land, it may be easier to introduce long-term sustainability thinking among them. As people only search for knowledge when they are aware of a problem [32], the non-participants may also not have been informed clearly about the Project's objectives and thus felt no need for IPM information.

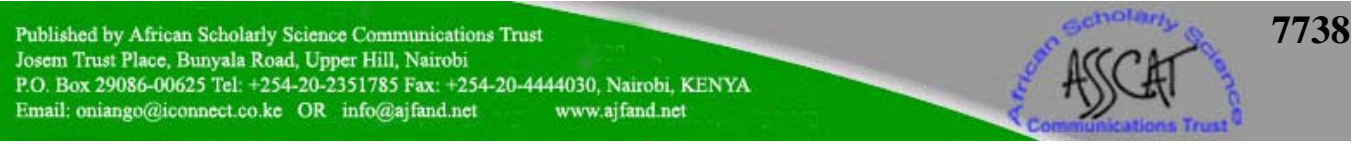




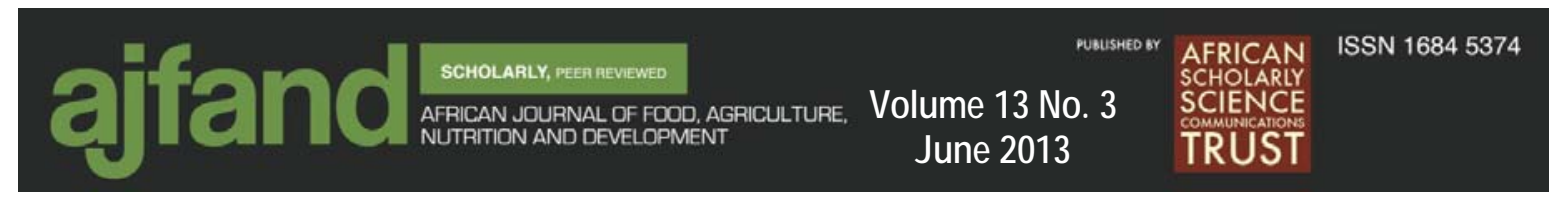

\section{Social relations, sustainability and institutionalization of IPM-FFS}

The participants had only used their gained ability to communicate, negotiate and argue in relation with IPM, and not to improve the social environment in the gardens. The existing environment of competition, mistrust and jealousy between the vegetable producers increased by the way the Project was implemented, and reduced the FFS participation. Although social impacts of FFS, like improved skills in team work and reaching consensus, reported elsewhere [7] did not occur in the Project, the social relations between the ToT participants and to some extent between these and other vegetable producers improved.

Lack of trust between the Project leaders and the vegetable producers may partly explain why the latter were not given more responsibility during the Project and ultimately felt no obligation to conduct post-IPM activities. This corresponds to Nathan [33] that people who are not given responsibility may feel lack of ownership and commitment to the processes. Also how the actors perceive their own roles influences their cooperation, as found in the CATIE/FFS project in Guatemala, where the project staffs ability to build the farmers' trust and feeling that all were at the same level was the most important in creating a free dialogue [17, 34, 35]. The Project in Cotonou experienced insufficient emphasis on building social relations among the steering committee members and gave them inadequate responsibility for post-IPM activities. It may be that IITA representatives found it difficult to change their roles from information deliverers to also being facilitators and to give up some control over the process. The IPM-FFS project in the Mwingi district in Kenya reported increased self-confidence of farmers and changes in the way they perceived their roles such that they dared to argue with the agrochemical salespersons [36]. In Sudan's Gezira Scheme the vegetable producers attending the IPM-FFS experienced increased empowerment and teamed up to increase their decision making power [37]. However, as in the case in Cotonou (explained in this current study), farmers with higher status were selected to become ToT in Sudan and this may have limited the impact of the training in the rural community [37].

Only farmers can institutionalize IPM at the community level [7], and local institutions need to be strengthened for sharing of information and experiences between more farmers and for maintaining relations with outside stakeholder groups [17]. While farmers in Kenya and DR Congo managed semi self-financed and selffinanced FFSs [20], the social challenges among vegetable producers and between these and the Project staff in Cotonou may have contributed to hinder the institutionalization of IPM-FFS. While Ghanaian FFS alumni created networks for knowledge exchange and support across villages and over half of the surveyed FFS graduates continued to meet as a group with other FFS alumni 2-3 years after the training without follow-up by a facilitator [30], another study from Ghana revealed the need to train and follow-up the facilitators to ensure the continuation of discovery learning and facilitation [38].

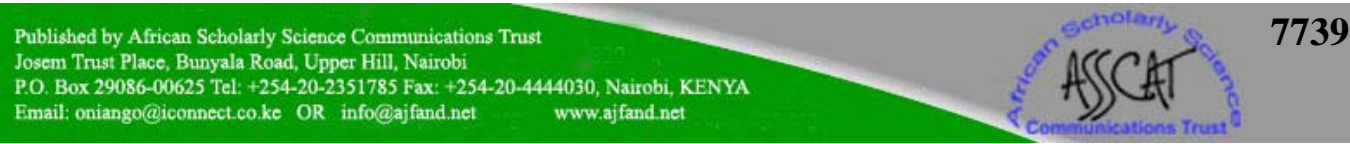




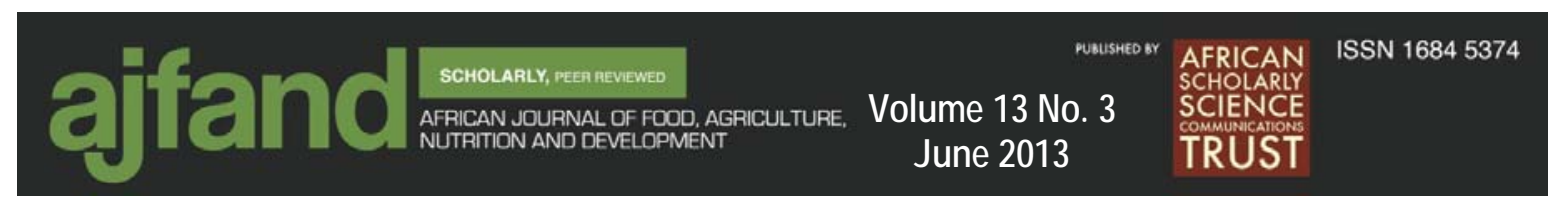

\section{CONCLUSIONS}

This study of the experiences of producers, trainers, researchers and institutions, involved in the vegetable IPM-FFS Project in Cotonou found that the ToT/FFS had empowering and social impacts for the participants, which enabled them to share information and knowledge, also with people they previously did not know. The Project initiated a process of sharing IPM knowledge where non-participants approached the ToT participants for advice. The specific social environment in the researched UPU gardens, which was characterised by competition, stark economic focus, insecure land tenure and availability of alternative income sources may have induced short-term thinking based on economic profit. This in turn may have reduced the vegetable producers' felt need for IPM information, thus deteriorating longer-term sustainability. This study also reveals several aspects related to project design that may hinder the creation of social relations and a social environment needed for enhanced sharing of IPM knowledge and institutionalization of IPM activities. Based on these findings, ways to enhance the social and institutional learning environment could include: (1) having transparent selection processes where all potential participants are informed and selection criteria, conditions and benefits of participation are made explicit, (2) enhance the ToTs' facilitation skills for better quality FFSs and improved sharing of complex information like agro-ecosystem analysis and beneficial organisms, (3) building trust and confidence between the participants and scientists, (4) giving the ToT participants, community organizers and farmer organizations ownership of the project by giving them responsibility for creating post project plans to spread and institutionalize IPM of IPM-FFS activities and (5) facilitating the participants in the project in improving social relations and accountability in a way so these will be sustained after the end of the project. In other words, to create a participatory IPM-FFS requires that all stakeholders (farmers, extension, researchers, NGOs) are involved in the process so they assume responsibility for the result. In doing so, the project would move much further in the direction of a farmer-focussed paradigm in agricultural development, where project leaders and scientists would change their roles from information deliverers to facilitators and resource persons who put the vegetable producers in the centre, both in terms of defining their own needs and sustaining the process in the future. Being a qualitative study of limited scope, the results cannot be automatically generalized. Nevertheless, in a wider context, this study provides ideas on how other FFS projects might better evaluate the extent to which they have moved from a mere transfer of IPM technology, into a knowledge sharing system where power relations, social networks, and institutionalization are integral parts of the development of any IPM endeavour.

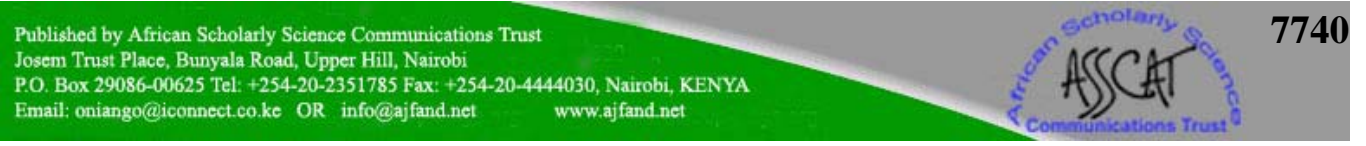




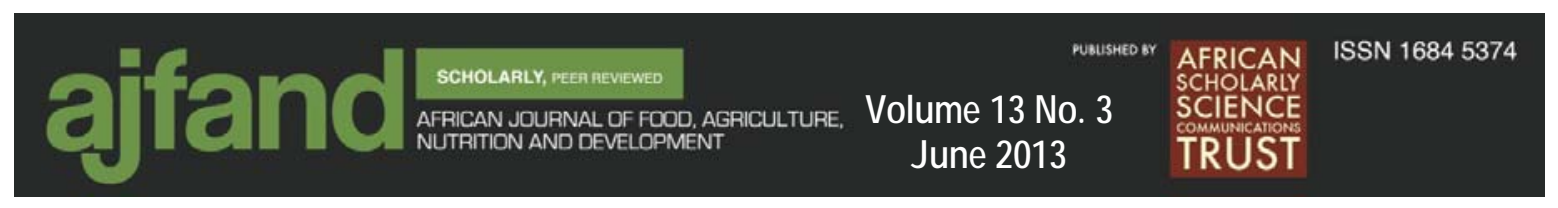

\section{ACKNOWLEDGEMENTS}

We wish to extend thanks to the vegetable producers in Cotonou, especially Edgard Deguenon, Albert Hagnilo and Amoussou Benoît, and to the staff at IITA-Benin, especially Braima James, Ignace Godonou, Cyprien Atcha-Ahowe, Brice Gbaguidi, Sounkoura Adetonah and Razack Adeoti. Thanks also go to friends in the MNRSA and librarians at UMB, and to Soniia David at IITA-Ghana, Nicoline de Hahn, Yacouba Bouraima, Benjamin Fayomi, Simplice Vodouhe, Joseph Gabin Dégbey and Sikirou Rachidatou. 


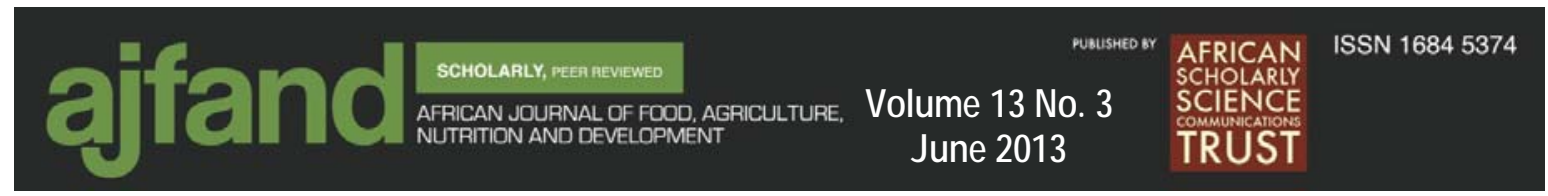

\section{REFERENCES}

1. UNFPA. Unleashing the potential of urban growth. State of the world 2007: (accessed 19.09.2008) Available from http://www.unfpa.org/swp/2007/english/introduction.html.

2. Nes A Evaluation of strawberry cultivars in Norway. In: H van der Scheer, F Lieten, and J Dijkstra (Eds.) ISHS Acta Horticulturae. III International Strawberry Symposium. Veldhoven: ISHS 1996: 275-280.

3. FAO. Issues in urban agriculture. FAO Agriculture and Consumer Protection Department 1999: (accessed 20.09.2008) Available from http://www.fao.org/ag/magazine/9901sp2.htm.

4. Prain G The institutional and regional context. In: G Prain, N Karanja, and D Lee-Smith (Eds.) African Urban Harvest. Agriculture in the cities of Cameroon, Kenya and Uganda. New York: Springer 2010.

5. Mancini F Impact of integrated pest management farmer field schools on health, farming systems, the environment, and livelihoods of cotton growers in Southern India. Wageningen: Wageningen University, Biological farming systems group 2006.

6. Douthwaite B, Weise S, Gockowski J, Keatinge D, Manyong V and D Baker IITA's Benchmark Area Approach: Putting INRM into Practice. INRM Workshop. Cali, Colombia: 2001.

7. Pontius J, Dilts $\mathbf{R}$ and A Bartlett From Farmer Field Schools to Community IPM: Ten years of building community IPM. Jakarta: FAO Community IPM programme 2000.

8. Fleischer G, Jungbluth F, Waibel $\mathbf{H}$ and JC Zadoks A field practioner's guide to economic evaluation of IPM. Pesticide Policy Project Publication Series. Vol. 9. Hannover: Uni Druck Hannover 1999.

9. Bacal R The Role of The Facilitator - Understanding What Facilitators Really DO! 2008: (accessed 19.09.2008) Available from http://www.work911.com/articles/facil.htm.

10. Page N and CE Czuba Empowerment: What Is It? Journal of extension 1999: (accessed 04.06.2008) Available from http://www.joe.org/joe/1999october/ent.html\#ed1.

11. Erbaugh JM, Donnermeyer J, Kibwika $\mathbf{P}$ and $\mathbf{S}$ Kyamanywa An assessment of the integrated pest management collaborative research support project's (IPM CRSP) activities in Uganda: Impact on farmers' awareness and knowledge of IPM skills. African Crop Science Journal 2002; 10: 271 - 280. 


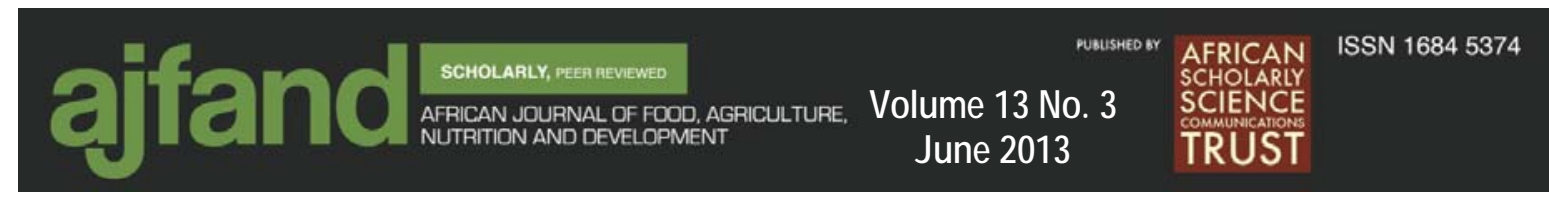

12. Godtland EM, Sadoulet E, Janvry Ad, Murgai R and O Ortiz The impact of farmer field schools on knowledge and productivity: A study of potato farmers in the Peruvian Andes. Chicago: University of Chicago 2004.

13. Rola AC, Quizon JB and SB Jamias Do Farmer Field School Graduates Retain and Share What They Learn?: An Investigation in Iloilo, Philippines. Journal of International Agricultural and Extension Education 2001; 9: 65-76.

14. Praneetvatakul S and $\mathbf{H}$ Waibel Farm Level and Environmental Impacts of Farmer Field Schools in Thailand. Development and Agricultural Economics, Faculty of Economics and Management, University of Hannover, Germany 2006.

15. Braun A and D Duveskog The Farmer Field School Approach - History, Global Assessment and Success Stories. Background Paper for the IFAD Rural Poverty Report 2010.

16. FAO. AGP - Integrated Pest Management. 2012: (accessed 25.08.2012)

Available from http://www.fao.org/agriculture/crops/core-

themes/theme/pests/ipm/en/.

17. Simpson $\mathbf{B M}$ and $\mathbf{M}$ Owens Farmer field schools and the future of agricultural extension in Africa. Proceedings of the 18th annual conference on approaches and partnerships for sustainable extension and rural development. Durban, South Africa, May 26 - 30, 2002: 2002.

18. Davis K, Nkonya E, Kato E, Mekonnen DA, Odendo M, Miiro R and J Nkuba Impact of Farmer Field Schools on Agricultural Productivity and Poverty in East Africa. 2010.

19. James B, Godonou I, Atcha C, Baimey H, Adango E, Boulga J and E Goudegnon Healthy vegetables through participatory IPM in peri-urban areas of Benin. Cotonou: IITA 2006.

20. Braun A, Jiggins J, Röling N, Berg Hvd and P Snijders A Global Survey and Review of Farmer Field School Experiences. Wageningen: International Livestock Research Institute 2006.

21. Carlberg E, Kostandini G and A Dankyi The Effects of Integrated Pest Management Techniques (IPM) Farmer Field Schools on Groundnut Productivity: Evidence from Ghana. Selected Paper prepared for presentation at the Agricultural \& Applied Economics Association's 2012 AAEA Annual Meeting, Seattle, Washington, August 12-14, 2012.

22. Mikkelsen B Methods for development work and research: a new guide for practitioners. 2 ed. London: Sage publication India Pvt Ltd 2005. 


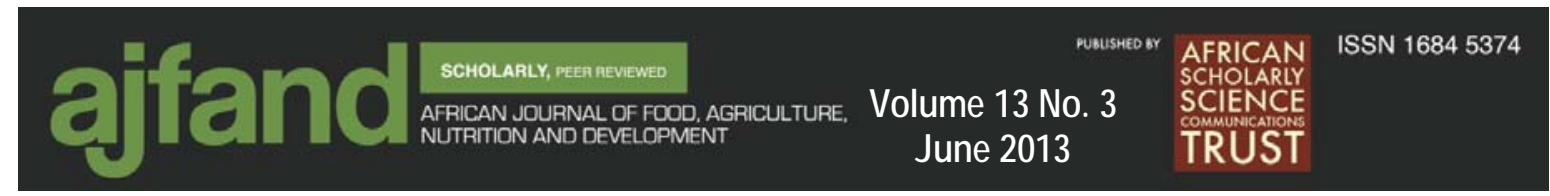

23. Bryman A Social research methods. New York: Oxford University Press Inc. 2004.

24. Social Perspective Network SPN goes east, in Progress 2005. 2005: Newmarket racecourse. October 112005.

25. Witt R, Waibel $\mathbf{H}$ and $\mathbf{D}$ Pemsl Diffusion of information among small-scale farmers in Senegal: the concept of Farmer Field Schools. Berlin: Verein für Socialpolitik, Research Committee Development Economics 2006.

26. Renko $\mathbf{Y}$, Autio $\mathbf{H}$ and $\mathbf{V}$ Tontti Social capital, knowledge, and the international growth of technology-based new firms. International Business Review 2002; 1 : 279-304.

27. Conley $\mathbf{T}$ and $\mathbf{C}$ Udry Social learning through networks: the adoption of new agricultural technologies in Ghana. American Journal Agricultural Economics 2001; 83: 668-732.

28. Katungi E, Edmeades $\mathbf{S}$ and $\mathbf{M}$ Smale Gender, Social Capital and Information Exchange in Rural Uganda. Washington: CAPRi 2006.

29. Nathaniels NQR Cowpea, farmer field schools and farmer-to-farmer extension: a Benin case study. Agricultural research \& extension network 2005: 1-15.

30. David S and C Asamoah The Impact of Farmer Field Schools on Human and Social Capital: A Case Study from Ghana. The Journal of Agricultural Education and Extension 2011; 17: 239-252.

31. Agli C, Adetonah S, Fagbemissi R, Lantokpode B, Nag A, Nathaniels N and Z Kakpo Tracing the effects of Farmer Field Schools within existing knowledge exchange networks: The case of cowpea in Benin. Cotonou: IITA 2002.

32. Rogers EM Diffusion of innovations. New York: The Free Press 1983.

33. Nathan L No Ownership, No Commitment: A Guide to Local Ownership of Security Sector Reform. Birmingham: University of Birmingham 2007.

34. Tollefson $\mathbf{L}$ and $\mathbf{M} \mathbf{W}$ ahab Irrigation Scheduling: From Theory to Practice Proceedings. Rome: ICID/FAO 1995.

35. Ugalde KA Perceptions and experiences with 'participatory approaches' in the CATIE/Norway project in Guatemala. MSc. Thesis. Ass: Norwegian University of Life Sciences, Noragric 2007. 


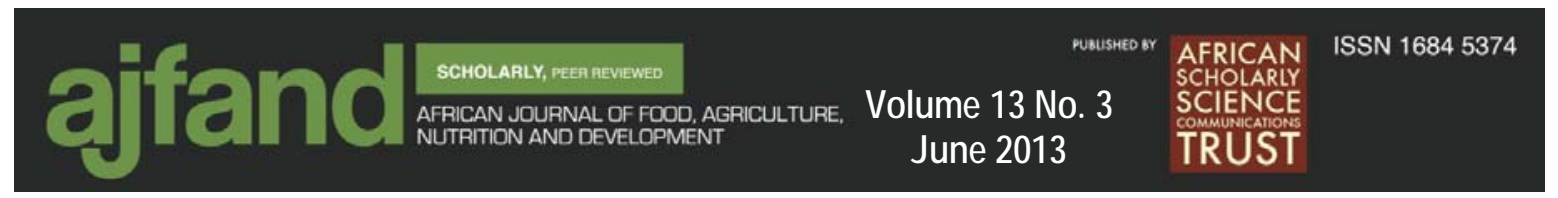

36. Duveskog $\mathbf{D}$ and E Friis-Hansen Farmer Field Schools: a platform for transformative learning in rural Africa. In: J Mezirow and E Taylor (Eds.) Transformative Learning in Action: Handbook of Practice: Jossey-Bass Press 2008.

37. Khalid A Assessing the long-term impact of IPM farmer field schools on farmers' knowledge, attitudes, practices and empowerment: a case study from Gezira Scheme, Sudan. In: CIP (Eds.) Farmer Field Schools: Emerging Issues and Challenges. Los Baños, Laguna, Philippines: International Potato Center 2002: 332-345.

38. David S and C Asamoah Farmer knowledge as an early indicator of IPM adoption: A case study from cocoa farmer field schools in Ghana. Journal of Sustainable Development in Africa 2011; 13: 213-224. 